\title{
Critical role of triglycerides for adiponectin levels in hepatitis C: a joint study of human and HCV core transgenic mice
}

Ming-Ling Chang ${ }^{1,2^{*}} \mathbb{0}$, Jing-Hong Hư ${ }^{3}$, Li-Heng Pao ${ }^{4,5}$, Ming-Shyan Lin ${ }^{6}$, Chia-Jung Kuo ${ }^{1,2}$, Shiang-Chi Chen, Chun-Ming Fan ${ }^{8}$, Ming-Yu Chang ${ }^{9,10}$ and Rong-Nan Chien ${ }^{1,2,11^{*}}$

\begin{abstract}
Background: Both hepatitis $\mathrm{C}$ virus ( $\mathrm{HCV}$ ) infection and adiponectin are critically involved in metabolism. The reversal and associations of altering adiponectin levels after sustained virological responses (SVRs) following direct-acting antivirals (DAA) in HCV-infected patients remained elusive.
\end{abstract}

Methods: A joint study was conducted in a prospective cohort of $427 \mathrm{HCV}$-infected patients and a line of HCV core transgenic mice.

Results: Of 427, 358 had completed a course of DAA therapy and 353 had SVRs. At baseline, male sex ( $95 \% \mathrm{Cl} \beta$ : -1.44 to -0.417$)$, estimated glomerular filtration rate (eGFR) $(-0.025$ to -0.008$)$, triglycerides $(-0.015$ to -0.005$)$, and fibrosis-4 levels (0.08-0.297) were associated with adiponectin levels; BMI (0.029-0.327) and triglycerides levels (0.01-0.03) were associated with homeostatic model assessment for insulin resistance (HOMA-IR) in HCV-infected patients. At 24-week post-therapy, in SVR patients, male sex $(-1.89$ to -0.5$)$ and eGFR $(-0.02$ to -0.001$)$ levels were associated with adiponectin levels, levels of BMI (0.094-0.335) and alanine transaminase (0.018-0.078) were associated with HOMA-IR; compared with baseline levels, adiponectin levels decreased $(6.53 \pm 2.77 \mathrm{vs} .5 .45 \pm 2.56 \mu \mathrm{g} / \mathrm{mL}$, $p<0.001)$. In 12-month-old HCV core transgenic mice with hepatic steatosis, triglyceride levels (0.021-0.111) were associated with adiponectin levels, and hepatic adipopnectin expression was comparable with that of control mice.

Conclusions: Triglycerides and hepatic fibrosis are associated with HCV-specific alteration of adiponectin levels, and adiponectin may affect insulin sensitivity through triglycerides during HCV infection. In DAA-treated patients, after SVR, adiponectin levels decreased and the linking function of triglycerides between adiponectin and insulin sensitivity vanished. Moreover, HCV core with hepatic steatosis might affect extrahepatic adiponectin expression through triglycerides.

Keywords: HCV, Adiponectin, Triglycerides, HOMA-IR, SVR, DAA, HCV core

*Correspondence: mlchang8210@gmail.com; ronald@cgmh.org.tw 1 Division of Hepatology, Department of Gastroenterology and Hepatology, Chang Gung Memorial Hospital, No 5, Fu Hsing Street, Kuei Shan, Taoyuan, Taiwan

Full list of author information is available at the end of the article

\section{Background}

Hepatitis $\mathrm{C}$ virus ( $\mathrm{HCV}$ ) is a human pathogen responsible for acute and chronic liver disease, chronically infecting an estimated 71.1 million individuals worldwide [1], and classified into 8 genotypes [2]. In addition to hepatic complications including steatosis, liver cirrhosis and hepatocellular carcinoma (HCC), HCV infection induces several extrahepatic complications, such as 
hypolipidemia, insulin resistance (IR), diabetes and cardiovascular events $[3,4]$. Thus, $\mathrm{HCV}$ is now considered to cause metabolic alterations instead of being simply a viral infection. The reversal of $\mathrm{HCV}$-associated metabolic alterations after sustained virological response (SVR) following interferon-based studies had been well demonstrated [3, 5-10]. However, some HCV-associated cardiometabolic events cannot be reversed, and HCVassociated HCC is also not eradicable after SVR $[3,11]$. Moreover, the reversal of metabolic alterations might be biased by interferon-based therapy, as interferon therapy has been associated with increases in lipid levels [12] and with immune modulation in the patients [13]. With the advent of direct-acting antivirals (DAAs), which target specific proteins of HCV during its life cycle [14], anti$\mathrm{HCV}$ treatment has resulted in a high cure rate with a short treatment duration in patients with chronic $\mathrm{HCV}$ infection $(\mathrm{CHC})$, and the reversal of $\mathrm{HCV}$-associated metabolic alterations might not be biased by any interferon-related effects.

Adiponectin, a $30-\mathrm{kDa}$ adipokine, is mainly expressed in adipocytes [15], while increased visceral adipose tissue stores reduce serum adiponectin [16]. It is the most abundantly secreted adipokine [17]. Several IR-associated hormones such as insulin and catecholamines dysregulate adiponectin expression [18]. Post-translational adiponectin modifications result in the secretion of oligomers of $90-\mathrm{kDa}$ trimers, found in the circulation. Adiponectin might protect hepatocytes from triglyceride accumulation by increasing $\beta$-oxidation, decreasing fatty acid de novo synthesis, and promoting the uptake and inhibiting the production of glucose in the liver $[19,20]$. Hepatic steatosis and hyperlipidemia are therefore usually associated with low adiponectin levels [20, 21]. Moreover, adiponectin possesses anti-inflammatory, anti-atherosclerotic and anti-apoptotic properties [22]. Paradoxically, circulating adiponectin levels have been associated with cardiovascular events and all-cause mortality [2325]. Because both HCV infection and adiponectin are deeply involved in metabolism, their relationship might aid to probe the therapeutic targets for $\mathrm{HCV}$-associated cardiometabolic complications. In $\mathrm{CHC}$ patients with SVRs following interferon-based therapy, adiponectin may affect insulin sensitivity through triglycerides. After viral clearance, adiponectin levels were directly associated with insulin sensitivity and decreased upon improved hepatic fibrosis [8]. However, how adiponectin levels evolve after SVR in CHC patients following DAA therapy remained unidentified and is crucial for the patients' prognosis, since interferon-based therapy had been replaced by DAA therapy as the standard of care treatment for CHC currently [26]. Being a HCV capsid protein, $\mathrm{HCV}$ core possesses the ability to interact with a variety of cellular components [27] and is the least variable of the $10 \mathrm{HCV}$ proteins in variant viruses emerging constantly in patients [28]. Our previous studies based on $\mathrm{HCV}$ core transgenic mice had shown that hepatic $\mathrm{HCV}$ core expression affects lipid metabolism genes [29], elicits mitochondrial stress [30], exhibits the topological and evolutional relationships with hepatic lipid vesicles [31] and alters the serum adiponectin levels in the non-obese mice with hepatic steatosis [32]. By taking advantage of this $\mathrm{HCV}$ core transgenic mice, the associated basis for $\mathrm{HCV}$-associated adiponectin level alteration might be uncovered.

Accordingly, we sought to elucidate the impact of $\mathrm{HCV}$ infection on adiponectin levels in a prospective study of $\mathrm{CHC}$ patients underwent DAA therapy. In parallel, the associated basis was elucidated via the serum biochemistry and immunohistochemistry (IHC) studies of the $\mathrm{HCV}$ core transgenic mice [29-32].

\section{Results}

Baseline characteristics of $\mathrm{CHC}$ patients

Of 427 CHC patients, 232 (54.3\%) were female patients, the mean age was 61.3 years. The males had higher levels of body mass index (BMI), alanine aminotransferase (ALT), the homeostatic model assessment for insulin resistance (HOMA-IR), uric acid (UA), model for endstage liver disease (MELD) score and ferritin and lower levels of total cholesterol (TC) and adiponectin than the females (Table 1).

\section{Baseline associations in $\mathrm{CHC}$ patients}

At baseline, for all $427 \mathrm{CHC}$ patients, male sex, estimated glomerular filtration rates (eGFRs) and levels of triglycerides (TG) were negatively, and levels of fibrosis-4 (FIB4) were positively associated with adiponectin levels (Table 2); levels of BMI and TG and HCV genotype other than 1, 2 and 3 (non-HCV G123) were positively associated with HOMA-IR (Table 3). While we stratified the patients with baseline insulin resistance (IR), non-HCV G123 were positively associated with HOMA-IR among those with baseline IR (Additional file 1: Table S2); BMI levels were associated with HOMA-IR levels among those without baseline IR (Additional file 1: Table S3).

\section{Post-therapy associations in SVR patients}

At 24 weeks post-therapy, among 353 SVR patients (Fig. 1), male sex and eGFRs were negatively associated with adiponectin levels (Table 4); levels of BMI and ALT were positively associated with HOMA-IR (Table 5). While we stratified the patients with baseline IR, among the SVR patients with baseline IR, levels of BMI were associated with HOMA-IR levels (Additional file 1: Table S4); levels of BMI, ALT and neutrophil 
Table 1 Baseline characteristics of the CHC patients

\begin{tabular}{|c|c|c|c|c|}
\hline & All $(n=427)$ & Male $(n=195)$ & Female $(n=232)$ & $p$ values * \\
\hline Age (years) & $61.3 \pm 12.8$ & $59.1 \pm 12.1$ & $61.3 \pm 12.8$ & 0.076 \\
\hline BMI $\left(\mathrm{kg} / \mathrm{m}^{2}\right)$ & $24.6 \pm 3.9$ & $25.1 \pm 3.46$ & $24.2 \pm 4.19$ & 0.012 \\
\hline \multicolumn{5}{|l|}{ HCV genotype } \\
\hline Genotype 1, n (\%) & $256(59.9)$ & $116(59.4)$ & $140(60.3)$ & 0.31 \\
\hline Genotype 2, n (\%) & $137(32.0)$ & $60(30.7)$ & $67(28.8)$ & 0.95 \\
\hline Genotype 3, n (\%) & $6(1.7)$ & $4(2)$ & $2(0.8)$ & 0.301 \\
\hline Log HCV RNA (logIU/mL) & $5.98 \pm 0.87$ & $5.96 \pm 0.92$ & $5.98 \pm 0.83$ & 0.813 \\
\hline $\operatorname{ALT}(U / L)$ & $79.8 \pm 90.4$ & $93.4 \pm 108.4$ & $68.5 \pm 71.6$ & 0.006 \\
\hline $\mathrm{eGFR}\left(\mathrm{mL} / \mathrm{min} / 1.73 \mathrm{~m}^{2}\right)$ & $86.9 \pm 41.7$ & $89.1 \pm 40.5$ & $85.0 \pm 42.8$ & 0.326 \\
\hline $\mathrm{TG}(\mathrm{mg} / \mathrm{dL})$ & $102.6 \pm 52.6$ & $105.9 \pm 58.5$ & $99.8 \pm 47.1$ & 0.235 \\
\hline $\mathrm{TC}(\mathrm{mg} / \mathrm{dL})$ & $169.5 \pm 35.3$ & $163.7 \pm 33.0$ & $174.4 \pm 36.5$ & 0.002 \\
\hline Fasting glucose (mg/dL) & $97.79 \pm 31.41$ & $100.10 \pm 39.07$ & $96.04 \pm 23.96$ & 0.066 \\
\hline Insulin $(\mu \mid \mathrm{U} / \mathrm{mL})$ & $10.18 \pm 30.01$ & $10.53 \pm 15.50$ & $9.92 \pm 37.29$ & 0.793 \\
\hline HOMA-IR & $3.17 \pm 4.88$ & $3.72 \pm 6.61$ & $2.77 \pm 2.56$ & 0.045 \\
\hline Uric acid (mg/dL) & $5.71 \pm 1.62$ & $6.17 \pm 1.69$ & $5.28 \pm 1.42$ & $<0.001$ \\
\hline NLR & $1.98 \pm 1.24$ & $2.06 \pm 1.19$ & $1.91 \pm 1.29$ & 0.248 \\
\hline Platelet (103/uL) & $176.8 \pm 71.7$ & $176.8 \pm 68.2$ & $176.7 \pm 74.8$ & 0.996 \\
\hline Liver cirrhosis, n (\%) & $92(21.5)$ & $40(20.9)$ & $52(22.4)$ & 0.699 \\
\hline Fibrosis-4 score & $3.53 \pm 3.39$ & $3.22 \pm 3.23$ & $3.79 \pm 3.51$ & 0.083 \\
\hline MELD score & $9.08 \pm 3.08$ & $9.51 \pm 4.00$ & $8.69 \pm 3.62$ & 0.022 \\
\hline Ferritin (ng/mL) & $376.1 \pm 513.2$ & $461.7 \pm 448.9$ & $298.1 \pm 555.3$ & 0.002 \\
\hline Adiponectin $(\mu \mathrm{g} / \mathrm{mL})$ & $6.52 \pm 2.71$ & $5.87 \pm 2.37$ & $7.06 \pm 2.85$ & $<0.001$ \\
\hline $\begin{array}{l}\text { IFNL3-rs12979860 } \\
\text { CC genotype, n (\%) }\end{array}$ & $1018(84.7)$ & $166(85.1)$ & $195(84.0)$ & 0.829 \\
\hline
\end{tabular}

CHC: chronic hepatitis C virus infection; DAA: direct-acting antivirals; BMI: body mass index; HCV: hepatitis C virus; RNA: ribonucleic acid; ALT: alanine transaminase; eGFR: estimated glomerular filtration rate; TG: triglycerides; TC: total cholesterol; HOMA-IR: homeostatic model assessment for insulin resistance; NLR: neutrophil lymphocyte ratio; IFNL3; interferon- $\lambda 3 .{ }^{*}, p$ values between male and female $\mathrm{CHC}$ patients

lymphocyte ratio (NLR) were associated with HOMA-IR levels among SVR patients without baseline IR (Additional file 1: Table S5).

\section{Variable alterations in SVR patients}

Compared with baseline levels, the SVR patients had decreased adiponectin levels, regardless of sex. Levels of ALT and eGFRs also decreased, while levels of BMI increased. By contrast, no differences were noted between pre- and post-therapy HOMA-IR levels among SVR patients. However, while we stratified the SVR patients by baseline IR, those with and without baseline IR had decreased and increased HOMA-IR levels, respectively (Table 6).

A summary of the associations and alterations of adiponectin and HOMA-IR levels was shown in Fig. 2.

\section{Serum biochemistry of the mice}

In 2-month-old tetracycline transactivator (tTA)-HCV core double transgenic $\mathrm{FVB} / \mathrm{N}$ mice (DTM), sex was associated with adiponectin levels; in 12-month-old
DTM, sex and TG levels were independently associated with adiponectin levels (Table 7).

\section{IHC studies of the mice}

The livers of tTA-HCV core DTM showed extensive $\mathrm{HCV}$ core expressions (Fig. 3A) and intracellular lipid accumulations (Fig. 3C). By contrast, the livers of tTA DTM did not show any HCV core expression (Fig. 3B) and only exhibited negligible intrahepatic lipids (Fig. 3D). Comparable hepatic adiponectin expressions were noted between the livers of single transgenic mice (STM) and DTM (Fig. 3E, F) ( $p=0.578)$.

\section{Discussion}

The most compelling results of the current study are as follows:

(1) At baseline, male sex, eGFRs, levels of TG, and FIB-4 were associated with adiponectin levels; levels of $\mathrm{BMI}$ and TG and $\mathrm{HCV}$ genotype were associated with HOMA-IR levels in CHC patients. (2) At 24 weeks posttherapy, male sex and eGFRs were associated with adiponectin levels; levels of BMI and ALT were associated 
Table 2 Associations of adiponectin levels in CHC patients at baseline

\begin{tabular}{|c|c|c|c|c|}
\hline \multirow[t]{2}{*}{ Baseline factors } & \multicolumn{2}{|l|}{ Univariate analyses } & \multicolumn{2}{|l|}{ Multivariate analyses } \\
\hline & $95 \% \mathrm{Cl}$ of $\beta(\beta)$ & $p$ values & $95 \% \mathrm{Cl}$ of $\beta(\beta)$ & $p$ values \\
\hline Male, yes & -1.74 to $-0.647(-1.194)$ & $<0.001$ & -1.44 to $-0.417(-0.93)$ & $<0.001$ \\
\hline Age (years) & $0.026-0.068(0.047)$ & $<0.001$ & -0.039 to $0.015(-0.012)$ & 0.394 \\
\hline $\mathrm{BMI}\left(\mathrm{kg} / \mathrm{m}^{2}\right)$ & -0.194 to $-0.159(-0.127)$ & $<0.001$ & -0.098 to $0.052(-0.023)$ & 0.545 \\
\hline HCV genotype & -0.146 to $0.143(0.014)$ & 0.868 & & \\
\hline Log HCV RNA (logIU/mL) & -0.507 to $0.176(-0.165)$ & 0.342 & & \\
\hline $\operatorname{ALT}(U / L)$ & -0.002 to $0.005(0.001)$ & 0.376 & & \\
\hline eGFR (mL/min/1.73 m²) & -0.025 to $-0.012(-0.019)$ & $<0.001$ & -0.025 to $-0.008(-0.017)$ & $<0.001$ \\
\hline $\mathrm{TG}(\mathrm{mg} / \mathrm{dL})$ & -0.018 to $-0.008(-0.013)$ & $<0.001$ & -0.015 to $-0.005(-0.01)$ & $<0.001$ \\
\hline $\mathrm{TC}(\mathrm{mg} / \mathrm{dL})$ & -0.004 to $0.013(-0.006)$ & 0.183 & & \\
\hline HOMA-IR & -0.177 to $-0.005(-0.061)$ & 0.034 & -0.052 to $0.053(0.00)$ & 0.99 \\
\hline Uric acid (mg/dL) & -0.312 to $0.077(-0.117)$ & 0.237 & & \\
\hline NLR & -0.321 to $0.203(-0.059)$ & 0.659 & & \\
\hline Platelet $\left(10^{3} / \mathrm{uL}\right)$ & -0.013 to $-0.006(-0.009)$ & $<0.001$ & -0.006 to $0.004(-0.001)$ & 0.617 \\
\hline Liver cirrhosis, yes & -0.391 to $0.948(0.279)$ & 0.414 & & \\
\hline Fibrosis-4 score & $0.17-0.324(0.247)$ & $<0.001$ & $0.08-0.297(0.188)$ & 0.001 \\
\hline Ferritin (ng/mL) & -0.001 to $0.000(0.000)$ & 0.212 & & \\
\hline $\begin{array}{l}\text { IFNL3-rs } 12979860 \\
\text { CC genotype, yes }\end{array}$ & -0.471 to $0.421(0.4752)$ & 0.324 & & \\
\hline
\end{tabular}

CHC: chronic hepatitis C virus infection; Cl: confidence interval; BMI: body mass index; HCV: hepatitis C virus; RNA: ribonucleic acid; ALT: alanine transaminase; eGFR: estimated glomerular filtration rate; TG: triglycerides; TC: total cholesterol; HOMA-IR: homeostatic model assessment for insulin resistance; NLR: neutrophil lymphocyte ratio; IFNL3; interferon- $\lambda 3$

Table 3 Associations of HOMA-IR levels in CHC patients at baseline

\begin{tabular}{|c|c|c|c|c|}
\hline \multirow[t]{2}{*}{ Baseline factors } & \multicolumn{2}{|l|}{ Univariate analyses } & \multicolumn{2}{|l|}{ Multivariate analyses } \\
\hline & $95 \% \mathrm{Cl}$ of $\beta(\beta)$ & $p$ values & $95 \% \mathrm{Cl}$ of $\beta(\beta)$ & $p$ values \\
\hline Male, yes & $0.081-1.964$ (1.022) & 0.033 & -1.44 to $-0.417(-0.93)$ & 0.100 \\
\hline Age (years) & -0.069 to $0.004(-0.032)$ & 0.085 & -0.039 to $0.015(-0.012)$ & 0.678 \\
\hline BMI $\left(\mathrm{kg} / \mathrm{m}^{2}\right)$ & $0.142-0.378(0.26)$ & $<0.001$ & $0.029-0.327(0.178)$ & 0.02 \\
\hline HCV genotype & $1.262-5.513(3.387)$ & 0.002 & $0.743-5.279(3.011)$ & 0.009 \\
\hline Log HCV RNA (logIU/mL) & 0.001 to $1.072(0.536)$ & 0.05 & -0.343 to $0.868(0.248)$ & 0.433 \\
\hline $\operatorname{ALT}(U / L)$ & -0.136 to $0.162(0.013)$ & 0.865 & & \\
\hline $\mathrm{eGFR}\left(\mathrm{mL} / \mathrm{min} / 1.73 \mathrm{~m}^{2}\right)$ & $0.000-0.023(0.012)$ & 0.043 & -0.013 to $0.023(0.005)$ & 0.575 \\
\hline $\mathrm{TG}(\mathrm{mg} / \mathrm{dL})$ & $0.015-0.033(0.024)$ & $<0.001$ & $0.01-0.03(0.02)$ & $<0.001$ \\
\hline $\mathrm{TC}(\mathrm{mg} / \mathrm{dL})$ & -0.015 to $0.012(-0.002)$ & 0.812 & & \\
\hline Adiponectin ( $\mu \mathrm{g} / \mathrm{mL})$ & -0.4 to $-0.016(-0.208)$ & 0.034 & -0.197 to 0.215 (0.009) & 0.932 \\
\hline Uric acid (mg/dL) & -0.141 to $0.541(0.2)$ & 0.25 & & \\
\hline NLR & -0.275 to $0.573(0.149)$ & 0.491 & & \\
\hline Platelet (103/uL) & -0.004 to 0.009 (0.002) & 0.489 & & \\
\hline Liver cirrhosis, yes & -0.692 to $1.595(0.451)$ & 0.438 & & \\
\hline Fibrosis-4 score & -0.183 to $0.188(-0.048)$ & 0.49 & & \\
\hline Ferritin (ng/mL) & $0.000-0.002(0.001)$ & 0.027 & 0.000 to $0.002(0.001)$ & 0.134 \\
\hline $\begin{array}{l}\text { IFNL3-rs12979860 } \\
\text { CC genotype, yes }\end{array}$ & -1.695 to 1.849 (0.077) & 0.932 & & \\
\hline
\end{tabular}

HOMA-IR: homeostatic model assessment for insulin resistance; CHC: chronic hepatitis C virus infection; Cl: confidence interval; BMI: body mass index; HCV: hepatitis C virus; RNA: ribonucleic acid; ALT: alanine transaminase; eGFR: estimated glomerular filtration rate; TG: triglycerides; TC: total cholesterol; NLR: neutrophil lymphocyte ratio; IFNL3; interferon- $\lambda 3$ 


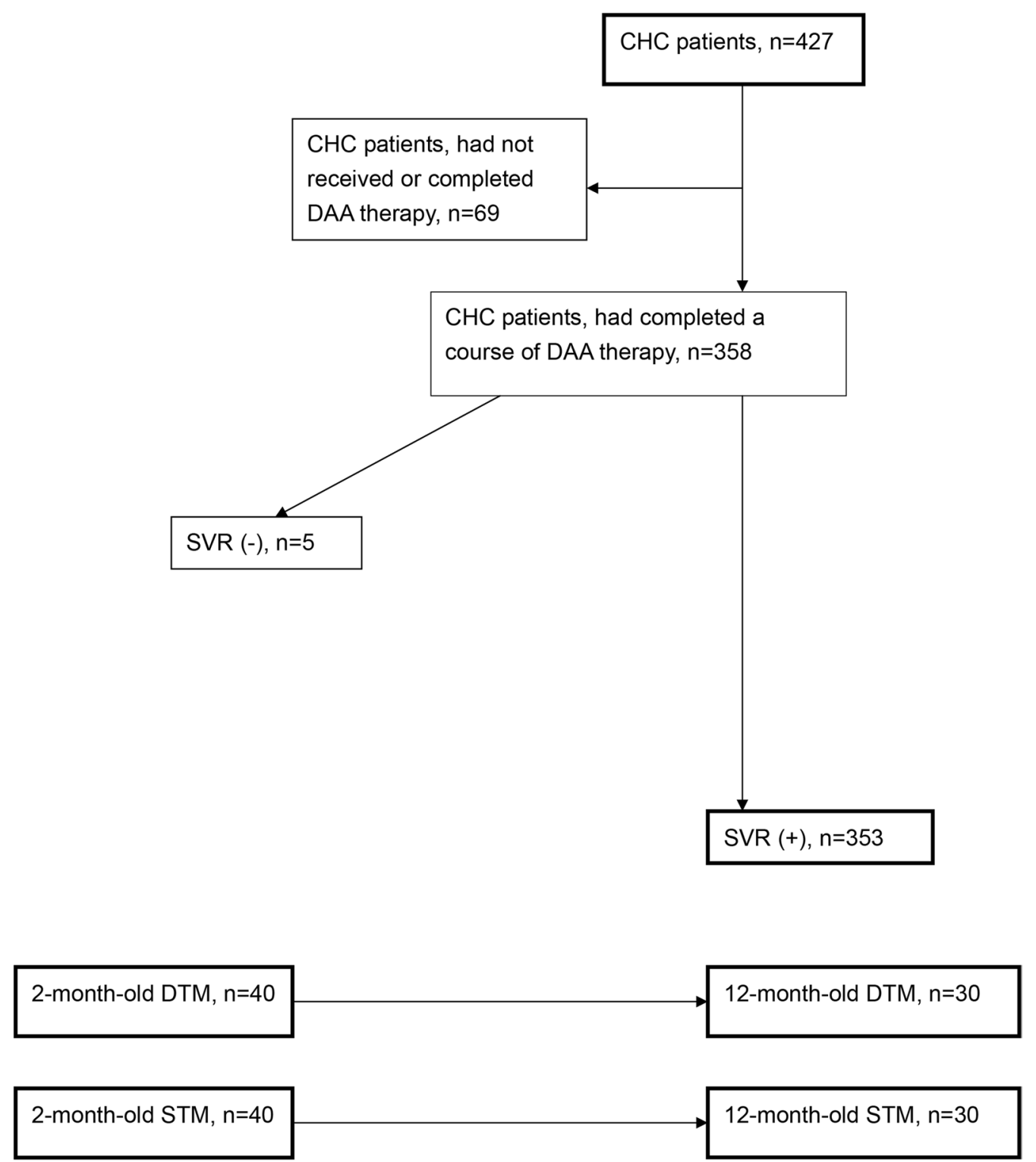

Fig. 1 A schematic flow chart of the enrolled patients and transgenic mice. CHC: chronic hepatitis C virus infection; DAA: direct acting antiviral; SVR: sustained virological response; DTM: tTA-HCV core double transgenic mice; STM: TTA single transgenic mice

with HOMA-IR levels in SVR patients; compared with baseline levels, adiponectin levels decreased, HOMAIR levels decreased and increased in those with and without baseline IR, respectively. (3) TG levels were independently associated with adiponectin levels in 12-month-old HCV core mice. (4) Comparable hepatic adiponectin expression was noted between tTA-HCV core DTM and tTA STM.

The comparisons of the baseline variables between the female and male $\mathrm{CHC}$ patients showed sex dimorphism in metabolic profiles [33] and adiponectin levels [16] and confirmed the reliability of the results of the current study. The factors consistently associated with adiponectin levels both pre-therapy in $\mathrm{CHC}$ patients and at 24 weeks post-therapy in SVR patients, such as sex and eGFR, disclosed their fundamental links of adiponectin, regardless of $\mathrm{HCV}$ infection. For example, higher adiponectin levels are usually noted in females than agematched males [16], and circulating adiponectin level is elevated in chronic kidney disease patients [34]. By contrast, the pre-therapy only factors such as TG and FIB-4, suggested the potential links, direct or indirect, between 
Table 4 Associations of adiponectin levels in SVR patients at 24 weeks post-therapy

\begin{tabular}{|c|c|c|c|c|}
\hline \multirow[t]{2}{*}{ 24-week post-therapy factors } & \multicolumn{2}{|l|}{ Univariate analyses } & \multicolumn{2}{|l|}{ Multivariate analyses } \\
\hline & $95 \% \mathrm{Cl}$ of $\beta(\beta)$ & $p$ values & $95 \% \mathrm{Cl}$ of $\beta(\beta)$ & $p$ values \\
\hline Male, yes & -1.708 to $-0.548(-1.128)$ & $<0.001$ & -1.89 to $-0.5(-1.195)$ & 0.001 \\
\hline Age, (years) & -0.01 to $0.037(0.013)$ & 0.252 & & \\
\hline $\mathrm{BMI}\left(\mathrm{kg} / \mathrm{m}^{2}\right)$ & -0.183 to $0.136(-0.11)$ & 0.004 & -0.139 to $0.16(-0.039)$ & 0.443 \\
\hline ALT $(U / L)$ & -0.042 to $-0.003(-0.023)$ & 0.024 & -0.04 to $0.004(-0.018)$ & 0.112 \\
\hline eGFR (mL/min/1.73 m²) & -0.024 to $-0.005(-0.015)$ & 0.002 & -0.02 to $-0.001(-0.011)$ & 0.034 \\
\hline $\mathrm{TG}(\mathrm{mg} / \mathrm{dL})$ & -0.008 to $-0.001(-0.005)$ & 0.007 & -0.005 to $0.002(-0.002)$ & 0.385 \\
\hline $\mathrm{TC}(\mathrm{mg} / \mathrm{dL})$ & -0.005 to $0.011(0.003)$ & 0.418 & & \\
\hline HOMA-IR & -0.153 to $0.045(-0.054)$ & 0.283 & & \\
\hline Uric acid (mg/dL) & -0.326 to $0.047(-0.14)$ & 0.141 & & \\
\hline NLR & -0.216 to 0.334 (0.059) & 0.673 & & \\
\hline Platelet (103/uL) & -0.01 to $0.00(-0.005)$ & 0.039 & & \\
\hline Liver cirrhosis, yes & -0.91 to $0.484(-0.213)$ & 0.548 & & \\
\hline Fibrosis-4 score & 0.026 to $0.265(0.146)$ & 0.017 & -0.044 to $0.197(21.72)$ & 0.077 \\
\hline Ferritin (ng/mL) & -0.001 to $0.001(0.000)$ & 0.904 & & \\
\hline $\begin{array}{l}\text { IFNL3-rs12979860 } \\
\text { CC genotype, yes }\end{array}$ & -0.502 to $1.038(0.268)$ & 0.494 & & \\
\hline
\end{tabular}

SVR: sustained virological response; BMI: body mass index; HCV: hepatitis C virus; RNA: ribonucleic acid; ALT: alanine transaminase; eGFR: estimated glomerular filtration rate; TG: triglycerides; TC: total cholesterol; HOMA-IR: homeostatic model assessment for insulin resistance; NLR: neutrophil lymphocyte ratio; IFNL3; interferon- $\lambda 3$

Table 5 Associations of HOMA-IR levels in SVR patients at 24 weeks post-therapy

\begin{tabular}{|c|c|c|c|c|}
\hline \multirow[t]{2}{*}{ 24-week post-therapy factors } & \multicolumn{2}{|l|}{ Univariate analyses } & \multicolumn{2}{|l|}{ Multivariate analyses } \\
\hline & $95 \% \mathrm{Cl}$ of $\beta(\beta)$ & $p$ values & $95 \% \mathrm{Cl}$ of $\beta(\beta)$ & $p$ values \\
\hline Male, yes & -0.2028 to 1.232 (0.515) & 0.158 & & \\
\hline Age, (years) & -0.041 to $0.015(-0.013)$ & 0.354 & & \\
\hline BMI $\left(\mathrm{kg} / \mathrm{m}^{2}\right)$ & $0.184-0.358(0.271)$ & $<0.001$ & $0.094-0.335(0.215)$ & 0.001 \\
\hline ALT (U/L) & $0.049-0.094(0.071)$ & $<0.001$ & $0.018-0.078(0.048)$ & 0.002 \\
\hline $\mathrm{eGFR}\left(\mathrm{mL} / \mathrm{min} / 1.73 \mathrm{~m}^{2}\right)$ & -0.0024 to 0.025 (0.011) & 0.102 & & \\
\hline $\mathrm{TG}(\mathrm{mg} / \mathrm{dL})$ & $0.006-0.014(0.01)$ & $<0.001$ & $0.000-0.01(0.005)$ & 0.057 \\
\hline TC (mg/dL) & -0.015 to $0.004(-0.005)$ & 0.271 & & \\
\hline Adiponectin $(\mu \mathrm{g} / \mathrm{mL})$ & -0.22 to $0.064(-0.078)$ & 0.283 & & \\
\hline Uric acid (mg/dL) & -0.1046 to $0.466(0.181)$ & 0.212 & & \\
\hline NLR & -6.116 to $4.889(-0.613)$ & 0.391 & & \\
\hline Platelet (103/uL) & -0.013 to $0.00(-0.007)$ & 0.059 & -0.013 to $0.002(-0.005)$ & 0.145 \\
\hline Liver cirrhosis, yes & $0.12-1.789(0.954)$ & 0.025 & -1.000 to $1.253(0.126)$ & 0.825 \\
\hline Fibrosis-4 score & -0.069 to $0.263(0.097)$ & 0.252 & & \\
\hline Ferritin (ng/mL) & $0.001-0.004(0.002)$ & 0.001 & $0.000-0.003(0.001)$ & 0.092 \\
\hline $\begin{array}{l}\text { IFNL3-rs12979860 } \\
\text { CC genotype, yes }\end{array}$ & -1.875 to $0.318(-0.778)$ & 0.163 & & \\
\hline
\end{tabular}

HOMA-IR: homeostatic model assessment for insulin resistance; SVR: sustained virological response; BMI: body mass index; HCV: hepatitis C virus; RNA: ribonucleic acid; ALT: alanine transaminase; eGFR: estimated glomerular filtration rate; TG: triglycerides; TC: total cholesterol; NLR: neutrophil lymphocyte ratio; IFNL3; interferon- $\lambda 3$

$\mathrm{HCV}$ infection and adiponectin levels. Consistent with our previous studies based on $\mathrm{CHC}$ patients with interferon-based therapy $[8,17]$, both TG and hepatic fibrosis
(FIB-4) were involved in $\mathrm{HCV}$-associated adiponectin alteration. In particular, during $\mathrm{HCV}$ infection, adiponectin might affect HOMA-IR levels through TG, 
Table 6 Comparisons between pre-therapy and 24-week post-therapy variables levels among CHC patients with SVRs

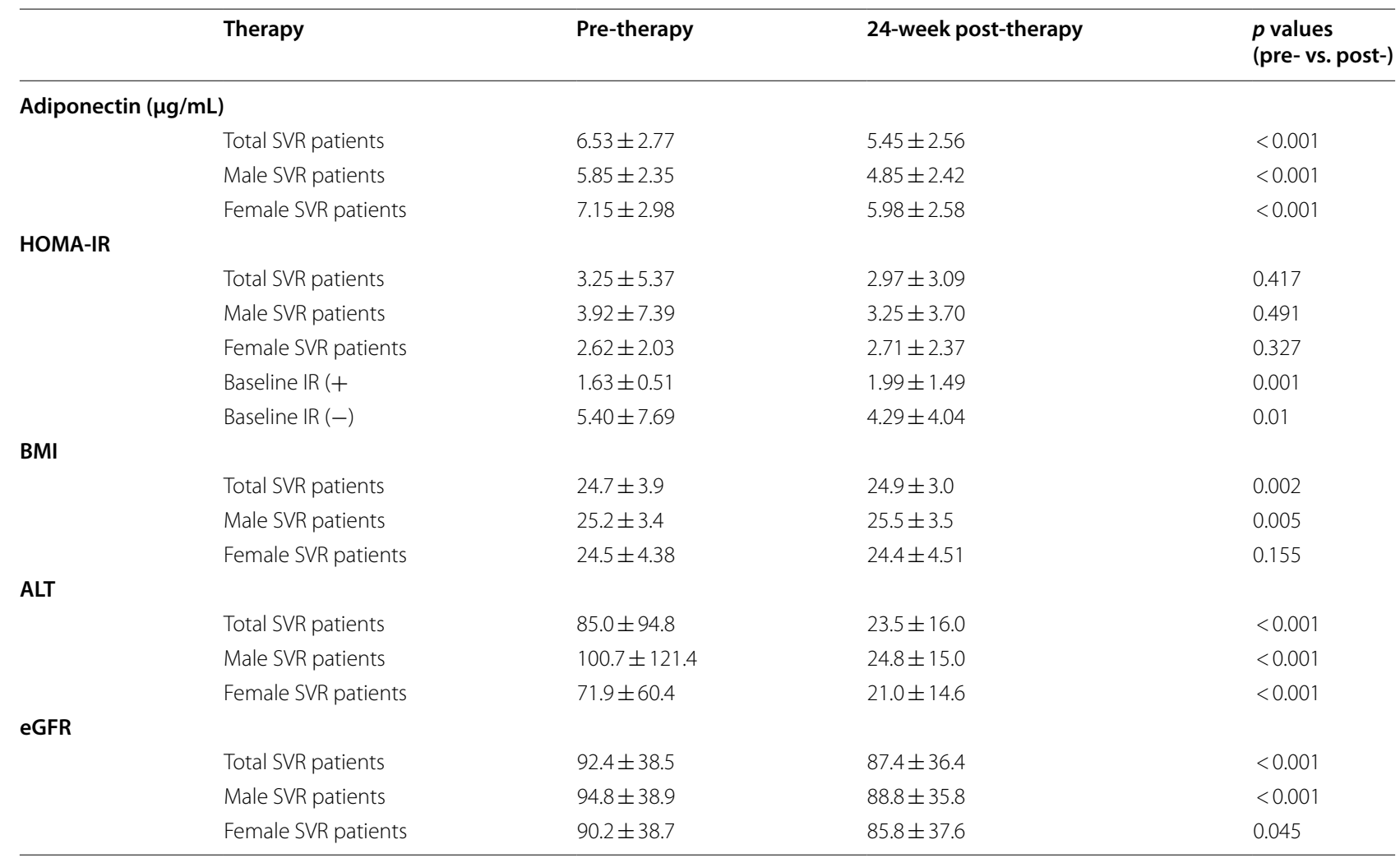

CHC: chronic hepatitis C virus infection; SVR: sustained virological response; HOMA-IR: homeostatic model assessment for insulin resistance; BMI: body mass index; ALT: alanine transaminase; eGFR: estimated glomerular filtration rate

and the link was more evident among those with than those without baseline IR. Moreover, adiponectin levels consistently decreased after SVR, and HOMA-IR levels decreased and increased in those with and without baseline IR, respectively, in both interferon-treated [8] and DAA-treated CHC patients (Fig. 2). The HCV-associated factors for adiponectin might account for the decreasing trend of adiponectin levels, since low TG and high FIB-4 levels in $\mathrm{CHC}$ patients before viral clearance [8] lead to high baseline adiponectin levels; after viral clearance, reversal of hypotriglycemia and improved hepatic fibrosis $[3,8]$ cause decreased adiponectin levels. On the other hand, several pro-inflammatory cytokines such as tumor necrosis factor- $\alpha$ (TNF- $\alpha$ ) and interleukin 6 , are reported to down-regulate the expression of adiponectin, resulting in decreased serum adiponectin levels $[18,35]$. In particular, activation of the TNF- $\alpha$ system has a pivotal role in the inflammatory process of $\mathrm{CHC}$, and TNF- $\alpha$ levels correlate with the degree of inflammation [36]. Anyhow, we trust that the inflammation was improved in $\mathrm{CHC}$ patients after viral clearance, evidenced by the decreased ALT and NLR levels in SVR patients. Thus, although TNF- $\alpha$ levels were not surveyed in the current study, TNF- $\alpha$ is less likely to be the culprit for decreased adiponectin levels in SVR patients. Of note, the direct association between HOMA-IR and adiponectin levels in SVR patients following interferon-based therapy [8] vanished in SVR patients following DAA therapy (Fig. 2). The various metabolic or immune microenvironments following various therapeutic regimens might account for the discrepancies. For example, ferritin levels reflect the iron homeostasis [37] and are involved in a wide range of physiologic and pathologic processes [38]; the serum ferritin levels increased in SVR patients following interferon-based therapy [39] but decreased SVR patients following DAA therapy $[40,41]$. Although the multivariate analyses in the current study did not show any independent role for ferritin levels in adiponectin and HOMA-IR levels, and the potential impact from ferritin on adiponectin and hOMA-IR levels, if any, might be indirect.

As the 12-month-old mice is equivalent to 58-yearold men [42], and the mean age of our human cohort is 61.3 years, the association of TG levels with adiponectin levels in 12-month-old HCV core transgenic mice echoes the crucial role of TG in affecting adiponectin levels in $\mathrm{CHC}$ patients and suggests the potential impact of $\mathrm{HCV}$ core on adiponectin levels. HCV core exhibits prominent topological relationship with intrahepatic lipid vesicles, 


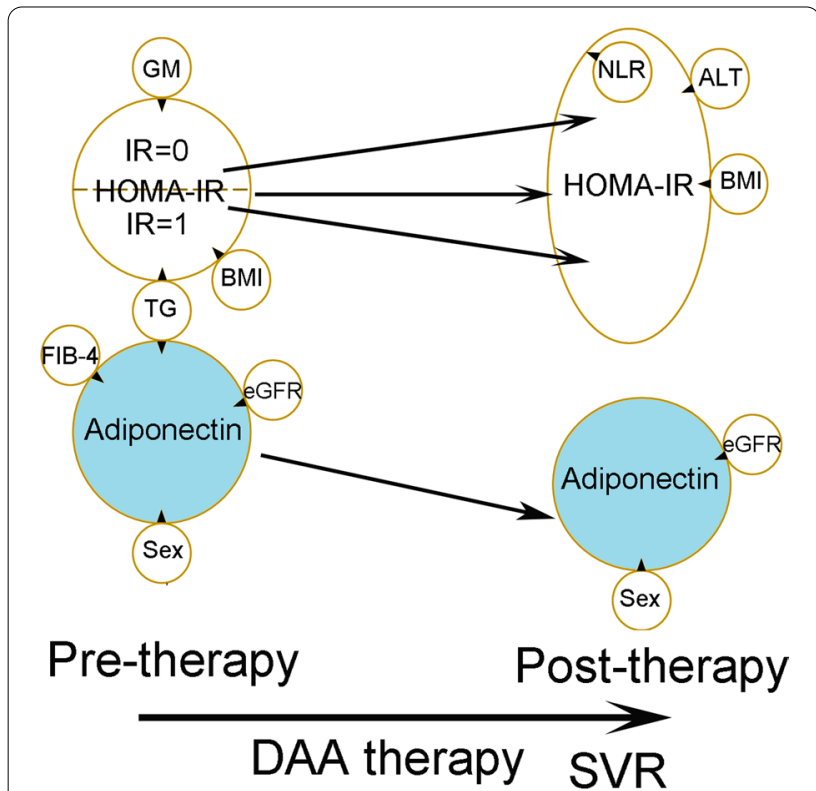

Fig. 2 The cross-sectional adiponectin and homeostasis model assessment-estimated insulin resistance (HOMA-IR)-centered associations between dependent and independent factors before (pre-therapy) and 24 weeks after DAA therapy (post-therapy). Tips of black arrowheads: dependent factors; bases of black arrowheads: independent factors; GM: HCV genotype; TG: triglycerides; IR: insulin resistance; BMI: body mass index; FIB-4: Fibrosis-4 index; pre-therapy: levels of variables before direct acting antiviral (DAA) therapy; eGFR: estimated glomerular filtration rate; NLR: neutrophil to lymphocyte ratio; ALT: alanine aminotransferase; SVR: sustained virological response. Rising arrow indicates post-therapeutic increases in HOMA-IR (baseline IR =0, ie. no baseline IR) levels, while descending arrows indicate post-therapeutic decreases in HOMA-IR (baseline $I R=1$, ie. with baseline $I R$ ) and adiponectin levels

which are mainly composed of TG [31]. Interestingly, the association between TG and adiponectin levels was not significant in the 2-month-old mice, which are equivalent to 20-year-old men [42]. Thus, the link between adiponectin and TG levels might not be evident until years of $\mathrm{HCV}$ infection in human. While that tTA-HCV core DTM (with hepatic steatosis) and tTA STM (without hepatic steatosis) had comparable hepatic adiponectin expression despite the different serum adiponectin levels [32] indicates that through interaction with TG, HCV core-related hepatic steatosis might alter adiponectin levels, via extrahepatic way.

\section{Conclusions}

Taken together, TG and fibrosis-4 levels are associated with HCV-specific alteration of adiponectin levels. Adiponectin may affect insulin sensitivity through TG during $\mathrm{HCV}$ infection. In DAA-treated $\mathrm{CHC}$ patients, after viral clearance, adiponectin levels decreased and the link function of TG between adiponectin and insulin sensitivity vanished. Additionally, $\mathrm{HCV}$ core with subsequent hepatic steatosis might affect extrahepatic adiponectin expression through TG. These findings might pave the way to probe the therapeutic target for cardiometabolic events in CHC patients after SVR following DAA therapy.

\section{Methods}

\section{Human study}

The study group comprised subjects aged 18 years or older with CHC. Subjects with human immunodeficiency virus, hepatitis B infection, hemochromatosis, primary biliary cholangitis, primary sclerosing cholangitis, autoimmune hepatitis or malignancy and recipients of solid organ transplants were excluded. $\mathrm{CHC}$ was defined as detectable HCV RNA for $>24$ weeks.

A total of $427 \mathrm{CHC}$ patients were consecutively recruited at a tertiary referral center between May 2015 and December 2019. Of the 427 patients, 358 (Fig. 1) had completed a course of anti-HCV therapy with

Table 7 Associations of adiponectin levels in HCV core transgenic mice

\begin{tabular}{|c|c|c|c|c|c|c|c|c|}
\hline & \multicolumn{4}{|l|}{ 2-month-old DTM } & \multicolumn{4}{|l|}{ 12-month-old DTM } \\
\hline & $95 \% \mathrm{Cl}$ of $\beta(\beta)$ & $p$ values & $95 \% \mathrm{Cl}$ of $\beta(\beta)$ & $p$ values & $95 \% \mathrm{Cl}$ of $\beta(\beta)$ & $p$ values & $95 \% \mathrm{Cl}$ of $\beta(\beta)$ & $p$ values \\
\hline Male, yes & $\begin{array}{l}-2.83 \text { to }-1.07 \\
(-1.90)\end{array}$ & $<0.001$ & $\begin{array}{l}-6.954 \text { to }-0.547 \\
(-3.75)\end{array}$ & 0.025 & -7.8 to $-2.5(-5.2)$ & 0.001 & $\begin{array}{l}-5.616 \text { to }-0.50 \\
(-3.059)\end{array}$ & 0.023 \\
\hline $\operatorname{ALT}(U / L)$ & $0.000-0.007(0.004)$ & 0.041 & $\begin{array}{c}-2.37 \text { to } 0.039 \\
(-0.099)\end{array}$ & 0.144 & $\begin{array}{l}-0.035 \text { to } 0.025 \\
(-0.005)\end{array}$ & 0.29 & & \\
\hline $\mathrm{TG}(\mathrm{mg} / \mathrm{dL})$ & $\begin{array}{l}-0.056 \text { to } 0.048 \\
(-0.004)\end{array}$ & 0.866 & & & $0.054-0.14(0.097)$ & $<0.001$ & $0.021-0.111(0.066)$ & 0.007 \\
\hline $\mathrm{TC}(\mathrm{mg} / \mathrm{dL})$ & $\begin{array}{l}-0.136 \text { to } 0.007 \\
(-0.065)\end{array}$ & 0.073 & $\begin{array}{l}-0.172 \text { to } 0.107 \\
(-0.032)\end{array}$ & 0.622 & $\begin{array}{l}-0.147 \text { to } 0.043 \\
(-0.052)\end{array}$ & 0.257 & & \\
\hline HOMA-IR & $\begin{array}{l}-0.343 \text { to } 0.221 \\
(-0.061)\end{array}$ & 0.662 & & & $\begin{array}{c}-0.891 \text { to } 0.493 \\
(-0.199)\end{array}$ & 0.536 & & \\
\hline
\end{tabular}

HCV: hepatitis C virus; DTM: tTA-HCV core double transgenic mice; ALT: alanine transaminase; eGFR: estimated glomerular filtration rate; TG: triglycerides; TC: total cholesterol; HOMA-IR: homeostatic model assessment for insulin resistance 

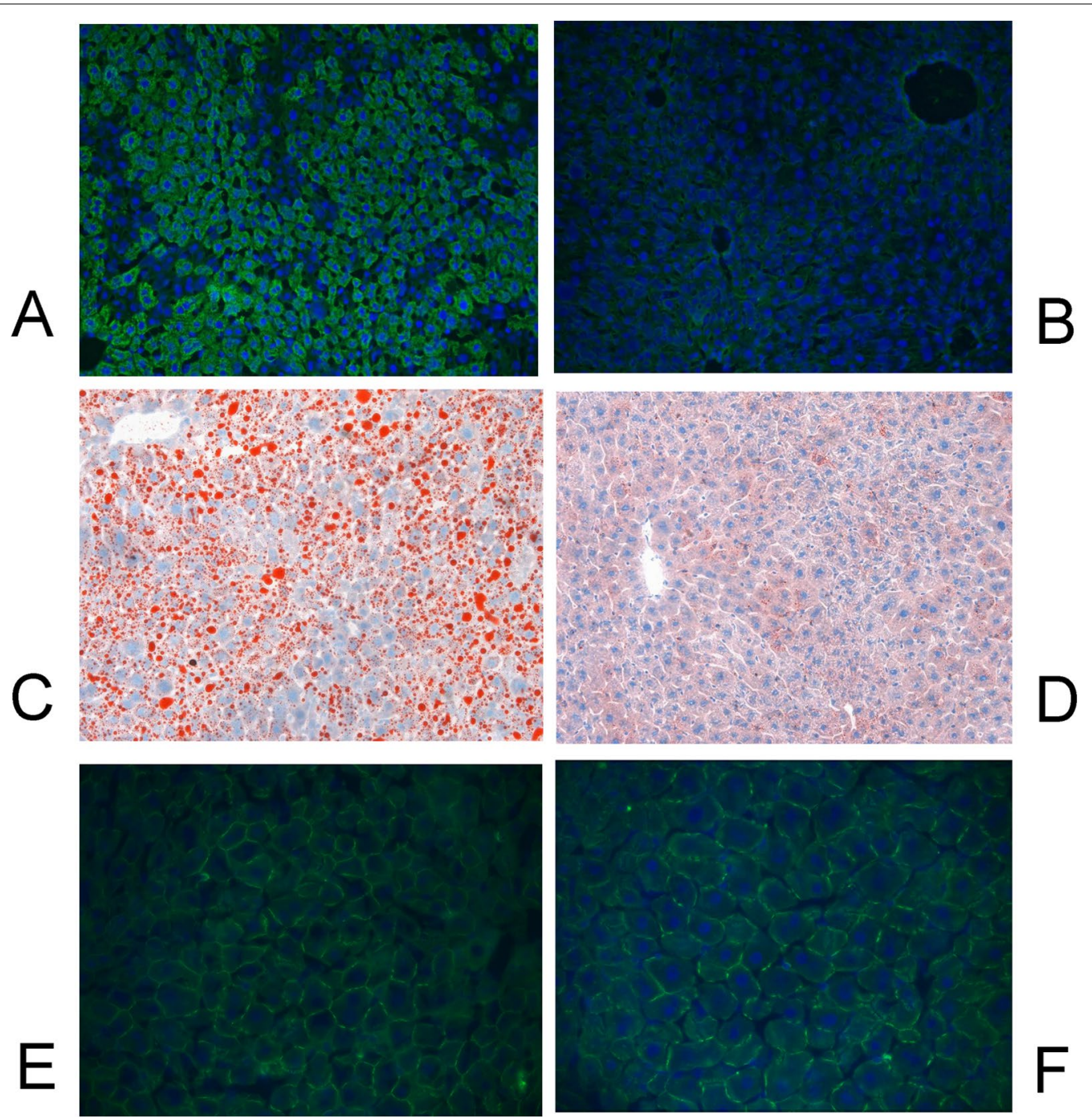

Fig. $3 \mathrm{HC}$ studies for HCV core (A and $\mathbf{B})$, lipid $(\mathbf{C}$ and $\mathbf{D})$ and adiponectin $(\mathbf{E}$ and $\mathbf{F})$ in the frozen liver samples of tTA-HCV core DTM $(\mathbf{A}, \mathbf{C}$ and $\mathbf{E})$ and tTA STM (B, D and F). The HCV core-positive cells were shown in green, the intracellular lipids were shown in red, the adiponectin was shown in green (in the cell borders)

various DAA combination (Additional file 1: Table S1) according to the reimburse policy of Bureau of National Health Insurance of the country and had been followed $\geq 24$ weeks after completion of DAA therapy. HCV RNA levels, genotypes, and single-nucleotide polymorphisms of interferon- $\lambda 3$-rs12979860 were assessed as previously described [5, 7, 21-25]. Several baseline factors including sex, age, body mass index, HCV genotype, levels of HCV RNA, eGFR, UA, TC, TG, fasting glucose, fasting insulin, HOMA-IR [fasting insulin $(\mu \mathrm{U} /$ $\mathrm{mL}) \times$ fasting glucose $(\mathrm{mmol} / \mathrm{L}) / 22.5]$, ALT and FIB-4 [(Age (years) $\times$ aspartate transaminase $(\mathrm{U} / \mathrm{L}) /$ (Platelets $\left(10^{9} / \mathrm{L}\right) \times(\sqrt{ }(\mathrm{ALT}(\mathrm{U} / \mathrm{L}))]$ index, MELD score, ferritin, adiponectin (R\&D Systems, MN, USA) and the presence of hepatic cirrhosis were checked and recorded for all enrolled patients at baseline. Biochemical tests were performed at the clinical pathology laboratories of the hospital using routine automated techniques. An SVR was defined as undetectable levels of HCV RNA 12 weeks after the completion of therapy. In total, 353 had SVRs (Fig. 1). An IR was defined as HOMA-IR $\geq 2.5$ [8]. The aforementioned variables were surveyed among the SVR patients at 24 weeks after the completion of therapy.

\section{Animal study}

tTA-HCV core DTM in which expression of the HCV core gene was suppressible by tetracycline were raised as previously described [29-32]. These mice were raised 
and maintained in the specific-pathogen-free rooms of the animal center of the hospital, the experimental mice were acquired from the animal center of the hospital. For both the DTM and tTA STM, analyses of HCV core protein expression was performed by IHC staining as described previously [29-32], fat vesicles were identified by Oil Red O staining of frozen sections according to the manufacturer's protocol (BioGenex, Fremont, $\mathrm{CA}$ ), and IHC studies of adiponectin (Novus Biologicals) were performed using frozen liver samples according to the manufacturer's protocols. Protein expression intensity was determined as described previously [10]. The fasting serum levels of adiponectin (R\&D Systems, Minneapolis, MN) and insulin (Crystal Chem, Downers Grove, IL) were surveyed by using enzyme-linked immunosorbent assay bioassay kits according to manufacturer's protocols in 2-month-old (males, $\mathrm{n}=20$, females, $\mathrm{n}=20$ ) and 12-month-old DTM (males, $\mathrm{n}=16$, females, $\mathrm{n}=14$ ) and in 2-month-old (males, $\mathrm{n}=20$, females, $\mathrm{n}=20$ ) and 12-month-old t-TA STM (males, $\mathrm{n}=15$, females, $\mathrm{n}=15$ ). The assays for fasting serum glucose, TG, TC and ALT levels (Vitros DT60 II Chemistry System; Johnson \& Johnson, Rochester, NY) were adopted for using tail blood according to the manufacturer's protocol in 2-month-old (males, $\mathrm{n}=20$, females, $\mathrm{n}=20$ ) and 12-month-old DTM (males, $\mathrm{n}=16$, females, $\mathrm{n}=14$ ). After the end of the experiments, all the mice were sacrificed with $\mathrm{CO} 2$ euthanasia by using the home cages.

A schematic flow chart for the enrolled patients and transgenic mice was shown as Fig. 1.

\section{Statistics}

All statistical analyses were performed using the Statistical Package for Social Science (SPSS package version 21, SPSS Inc., Chicago, IL, USA) or MedCalc (MedCalc ver. 12.4, MedCalc Software Corp., Acacialaan, Ostend, Belgium) software. The continuous variables are summarized as means \pm standard deviations $(\mathrm{SD})$, and the categorical variables are summarized as frequencies and percentages. The t-tests or Chi Square tests were applied for compared the variables between 2 groups while indicated. Multivariate linear regression models were used to assess the relationships between various dependent and independent factors by adjusting for all independent variables with $p$ values $<0.1$ in the univariate analyses. Repeated measures or Wilcoxon signed-rank tests were performed for the same variable measured in the same or matched subjects $\geq 2$ time periods. Statistical significance was defined at the $5 \%$ level based on two-tailed tests.

\section{Abbreviations}

HCV: Hepatitis C virus; SVRs: Sustained virological responses; DAA: Direct-acting antivirals; eGFR: Estimated glomerular filtration rate; HOMA-IR: Homeostatic model assessment for insulin resistance; HCC: Hepatocellular carcinoma; IR: Insulin resistance; CHC: Chronic HCV infection; IHC: Immunohistochemistry; BMI: Body mass index; TG: Triglycerides; tTA: Tetracycline transactivator; DTM: Double transgenic mice; STM: Single transgenic mice.

\section{Supplementary Information}

The online version contains supplementary material available at https://doi. org/10.1186/s12865-021-00445-5.

Additional file 1. Supplementary Table 1. Various DAA combinations used in the study. Supplementary Table 2. Associations of HOMA-IR levels in CHC patients with baseline IR at baseline. Supplementary Table 3. Associations of HOMA-IR levels in $\mathrm{CHC}$ patients without baseline IR at baseline. Supplementary Table 4. Associations of HOMA-IR levels in SVR patients with baseline IR at 24 weeks post-therapy. Supplementary Table 5. Associations of HOMA-IR levels in SVR patients without baseline IR at 24 weeks post-therapy

\section{Acknowledgements}

The authors thank Ms. Shu-Chun Chen, Ms. Chia-Hui Tsai, Mr. Chun-Kai Liang and Mr. Shuen-Shian Shiau from Division of Hepatology, Department of Gastroenterology, Chang Gung Memorial Hospital, Taiwan, for their assistance with data mining.

\section{Authors' contributions}

LHP and MYC collected and analyzed the data and wrote the manuscript. JHH, MSL, CJK, SCC and CMF interpreted the data and wrote the manuscript. MLC and RNC designed and completed the study, drafted the article and critically revised it for intellectual content. All authors read and approved the final version of the article, including the authorship list.

\section{Funding}

This study was supported by grants from the Chang Gung Medical Research Program (CMRPG3I0412, CMRPG3K0721 and CMRPG1K0111) and the National Science Council, Taiwan (MOST 110-2314-B-182-044-, 110-2629-B-182-001-, 1092314-B-182-024- and 109-2629-B-182-002-). The funders had no role in study design, data collection and analysis, decision to publish, or preparation of the manuscript.

\section{Availability of data and materials}

The datasets used and/or analyzed during the current study are available from the corresponding author on reasonable request. Because part of our data will be further analyzed for other study, we thus did not deposit the datasets in any publicly available repositories.

\section{Declarations}

Ethics approval and consent to participate

Written informed consent was obtained from each patient. The study protocols for human and animal studies conformed to the ethical guidelines of the 1975 Declaration of Helsinki and were approved by the Chang Gung Medical Foundation Institutional Review Board (IRB) (IRB No. 201801511B0) and Institutional Animal Care and Use Committee (IACUC) (IACUC No. 2018091701).

Consent for publication

Not applicable.

Informed consent

Written informed consent was obtained from each patient. The study protocols for human and animal studies conformed to the ethical guidelines of 
the 1975 Declaration of Helsinki and were approved by the local institutional review board.

\section{Competing interests}

The authors declare no competing interests.

\section{Author details}

'Division of Hepatology, Department of Gastroenterology and Hepatology, Chang Gung Memorial Hospital, No 5, Fu Hsing Street, Kuei Shan, Taoyuan, Taiwan. ${ }^{2}$ Department of Medicine, College of Medicine, Chang Gung University, Taoyuan, Taiwan. ${ }^{3}$ Department of Internal Medicine, Chang Gung Memorial Hospital, Yunlin, Taiwan. ${ }^{4}$ Graduate Institute of Health-Industry Technology, Chang Gung University of Science and Technology, Taoyuan, Taiwan. ${ }^{5}$ Research Center for Industry of Human Ecology, Chang Gung University of Science and Technology, Taoyuan, Taiwan. ${ }^{6}$ Department of Cardiology, Heart Failure Center, Chang Gung Memorial Hospital, Yunlin, Taiwan. ${ }^{7}$ Department of Nursing, Taipei Medical University, Taipei, Taiwan. ${ }^{8}$ Department of Biomedical Sciences, Chang Gung University, Taoyuan, Taiwan. ${ }^{9}$ Division of Pediatric Neurologic Medicine, Chang Gung Children's Hospital, Taoyuan, Taiwan. ${ }^{10}$ Division of Pediatrics, Chang Gung Memorial Hospital, Keelung, Taiwan. ${ }^{11}$ Liver Research Unit, Department of Gastroenterology and Hepatology, Chang Gung Memorial Hospital, No 5, Fu Hsing Street, Kuei Shan, Taoyuan, Taiwan.

Received: 4 May 2020 Accepted: 29 July 2021

Published online: 11 August 2021

\section{References}

1. Spearman CW, Dusheiko GM, Hellard M, Sonderup M. Hepatitis C. Lancet. 2019;394(10207):1451-66.

2. Borgia SM, Hedskog C, Parhy B, Hyland RH, Stamm LM, Brainard DM, et al. Identification of a Novel Hepatitis C Virus Genotype from Punjab, India: expanding classification of hepatitis c virus into 8 genotypes. J Infect Dis. 2018;218(11):1722-9.

3. Chang ML. Metabolic alterations and hepatitis C: from bench to bedside. World J Gastroenterol. 2016;22(4):1461-76.

4. Chang ML, Yang SS. Metabolic signature of hepatic fibrosis: from individual pathways to systems biology. Cells. 2019;8(11):1423.

5. Chang ML, Lin YS, Chang MY, Hsu CL, Chien RN, Fann CS. Accelerated cardiovascular risk after viral clearance in hepatitis $C$ patients with the NAMPTrs61330082 T genotype: an 8-year prospective cohort study. Virulence. 2021;12(1):270-80

6. Chang SW, Cheng ML, Shiao MS, Yeh CT, Wang CH, Fan CM, et al. Recovery of lipid metabolic alterations in hepatitis $C$ patients after viral clearance: Incomplete restoration with accelerated $\omega$-oxidation. J Clin Lipidol. 2018;12(3):756-66.

7. Chang ML, Lin YS, Pao LH, Huang HC, Chiu CT. Link between plasminogen activator inhibitor-1 and cardiovascular risk in chronic hepatitis $\mathrm{C}$ after viral clearance. Sci Rep. 2017;7:42503.

8. Chang ML, Kuo CJ, Pao LH, Hsu CM, Chiu CT. The evolving relationship between adiponectin and insulin sensitivity in hepatitis $C$ patients during viral clearance. Virulence. 2017;8(7):1255-64.

9. Chang ML, Chen WT, Hu JH, Chen SC, Gu PW, Chien RN. Altering retinol binding protein 4 levels in hepatitis C: Inflammation and steatosis matter. Virulence. 2020;11(1):1501-11.

10. Chang ML, Liang KH, Ku CL, Lo CC, Cheng YT, Hsu CM, et al. Resistin reinforces interferon $\lambda-3$ to eliminate hepatitis $C$ virus with fine-tuning from RETN single-nucleotide polymorphisms. Sci Rep. 2016;6:30799.

11. Toyoda H, Kumada T, Tada T, Kiriyama S, Tanikawa M, Hisanaga Y, et al. Risk factors of hepatocellular carcinoma development in non-cirrhotic patients with sustained virologic response for chronic hepatitis C virus infection. J Gastroenterol Hepatol. 2015;30(7):1183-9.

12. Hamamoto S, Uchida Y, Wada T, Moritani M, Sato S, Hamamoto N, et al. Changes in serum lipid concentrations in patients with chronic hepatitis $C$ virus positive hepatitis responsive or non-responsive to interferon therapy. J Gastroenterol Hepatol. 2005;20:204-8.

13. Teijaro JR. Pleiotropic roles of type 1 interferons in antiviral immune responses. Adv Immunol. 2016;132:135-58.
14. Halfon P, Locarnini S. Hepatitis $C$ virus resistance to protease inhibitors. J Hepatol. 2011;55(1):192-206.

15. Yamauchi T, Kamon J, Ito Y, Tsuchida A, Yokomizo T, Kita S, et al. Cloning of adiponectin receptors that mediate antidiabetic metabolic effects. Nature. 2003;423(6941):762-9.

16. Chang ML, Hsu CM, Tseng JH, Tsou YK, Chen SC, Shiau SS, et al. Plasminogen activator inhibitor-1 is independently associated with non-alcoholic fatty liver disease whereas leptin and adiponectin vary between genders. J Gastroenterol Hepatol. 2015;30(2):329-36.

17. Chang ML, Hsu CM, Lin CH, Lin CY, Kuo CJ, Huang SW, et al. The Evolving Interplay among Abundant Adipokines in Patients with Hepatitis C during Viral Clearance. Nutrients. 2017;9(6):570.

18. Duntas LH, Popovic V, Panotopoulos G. Adiponectin: novelties in metabolism and hormonal regulation. Nutr Neurosci. 2004;7(4):195-200.

19. Stern JH, Rutkowski JM, Scherer PE. Adiponectin, leptin, and fatty acids in the maintenance of metabolic homeostasis through adipose tissue crosstalk. Cell Metab. 2016;23(5):770-84.

20. Guo R, Nair S, Zhang Y, Ren J. Adiponectin deficiency rescues high-fat dietinduced hepatic injury, apoptosis and autophagy loss despite persistent steatosis. Int J Obes (Lond). 2017;41(9):1403-12.

21. Wanders D, Plaisance EP, Judd RL. Lipid-lowering drugs and circulating adiponectin. Vitam Horm. 2012;90:341-74.

22. Aprahamian TR, Sam F. Adiponectin in cardiovascular inflammation and obesity. Int J Inflam. 2011;2011:376909.

23. Wu ZJ, Cheng YJ, Gu WJ, Aung LH. Adiponectin is associated with increased mortality in patients with already established cardiovascular disease: a systematic review and meta-analysis. Metabolism. 2014;63(9):1157-66.

24. Karas MG, Benkeser D, Arnold AM, Bartz TM, Djousse L, Mukamal KJ, et al. Relations of plasma total and high-molecular-weight adiponectin to new-onset heart failure in adults $\geq 65$ years of age (from the Cardiovascular Health study). Am J Cardiol. 2014;113(2):328-34.

25. Ye J, Liang Z, Liang Q, Zhang J, Mao S, Liang R. Adiponectin is associated with poor prognosis in carcinoma patients: evidence from a meta-analysis. Lipids Health Dis. 2015;14:154.

26. Chhatwal J, He T, Hur C, Lopez-Olivo MA. Direct-Acting Antiviral Agents for Patients With Hepatitis C Virus Genotype 1 Infection Are Cost-Saving. Clin Gastroenterol Hepatol. 2017;15(6):827-837.e8.

27. Gawlik K, Gallay PA. HCV core protein and virus assembly: what we know without structures. Immunol Res. 2014;60(1):1-10.

28. Cristina J, del Pilar MM, Moratorio G. Hepatitis C virus genetic variability in patients undergoing antiviral therapy. Virus Res. 2007;127(2):185-94.

29. Chang ML, Yeh CT, Chen JC, Huang CC, Lin SM, Sheen IS, et al. Altered expression patterns of lipid metabolism genes in an animal model of HCV core-related, nonobese, modest hepatic steatosis. BMC Genomics. 2008;9:109.

30. Chang ML, Chen JC, Chang MY, Yeh CT, Lin WP, Liang CK, et al. Acute expression of hepatitis $C$ core protein in adult mouse liver: Mitochondrial stress and apoptosis. Scand J Gastroenterol. 2008;43(6):747-55.

31. Chang ML, Chen JC, Yeh CT, Sheen IS, Tai DI, Chang MY, et al. Topological and evolutional relationships between HCV core protein and hepatic lipid vesicles: studies in vitro and in conditionally transgenic mice. World J Gastroenterol. 2007;13(25):3472-7.

32. Chang ML, Yeh HC, Tsou YK, Wang CJ, Cheng HY, Sung CM, et al. HCV coreinduced nonobese hepatic steatosis is associated with hypoadiponectinemia and is ameliorated by adiponectin administration. Obesity (Silver Spring). 2012;20(7):1474-80.

33. Li XD, Qiu BH, Su FC, Sun SX. Gender impacts on the correlations between nonalcoholic fatty liver disease and hypertension in a Chinese population aged 45-60 y. Clin Exp Hypertens. 2016;38(7):639-43.

34. Kim H, Yun HR, Park S, Jhee JH, Park JT, Yoo TH, et al. High serum adiponectin is associated with anemia development in chronic kidney disease: The results from the KNOW-CKD study. Cytokine. 2018;103:1-9.

35. Andrade-Oliveira V, Câmara NO, Moraes-Vieira PM. Adipokines as drug targets in diabetes and underlying disturbances. J Diabetes Res. 2015;2015:681612.

36. Knobler $\mathrm{H}$, Schattner A. TNF-alpha, chronic hepatitis $\mathrm{C}$ and diabetes: a novel triad. QJM. 2005;98(1):1-6.

37. Fiorelli G. Serum ferritin and erythrocyte indices in iron overload. Blood Transfus. 2007;5(4):187-8.

38. Knovich MA, Storey JA, Coffman LG, Torti SV, Torti FM. Ferritin for the clinician. Blood Rev. 2009;23(3):95-104. 
39. Mangia A, Sarli R, Gamberini R, Piga A, Cenderello G, Piazzolla V, et al. Randomised clinical trial: sofosbuvir and ledipasvir in patients with transfusiondependent thalassaemia and HCV genotype 1 or 4 infection. Aliment Pharmacol Ther. 2017:46(4):424-31.

40. Origa R, Ponti ML, Filosa A, Galeota Lanza A, Piga A, Saracco GM, et al. Treatment of hepatitis $C$ virus infection with direct-acting antiviral drugs is safe and effective in patients with hemoglobinopathies. Am J Hematol. 2017;92(12):1349-55.

41. Chang ML, Hu JH, Yen CH, Chen KH, Kuo CJ, Lin MS, et al. Evolution of ferritin levels in hepatitis $C$ patients treated with antivirals. Sci Rep. 2020;10(1):19744
42. http://www.age-converter.com/mouse-age-calculator.html

\section{Publisher's Note}

Springer Nature remains neutral with regard to jurisdictional claims in published maps and institutional affiliations.
Ready to submit your research? Choose BMC and benefit from:

- fast, convenient online submission

- thorough peer review by experienced researchers in your field

- rapid publication on acceptance

- support for research data, including large and complex data types

- gold Open Access which fosters wider collaboration and increased citations

- maximum visibility for your research: over $100 \mathrm{M}$ website views per year

At BMC, research is always in progress.

Learn more biomedcentral.com/submissions 